\title{
Mobile-aided diagnosis systems are the future of health care
}

Donia Ben Hassen ${ }^{1}$

${ }^{1}$ Higher School of Digital Economy, University of Manouba, Tunisia (Correspondence to: D. Ben Hassen: donia.ben.hassen@esen.tn)

\begin{abstract}
Technology has been a driving force in changing the routine duties of physicians. Advances in mobile technologies have given rise to a new term: $\mathrm{mHealth}$ (mobile Health). mHealth devices generate big data and integration of mHealth and big data into existing eHealth services, and the continued growth in coverage of mobile cellular networks are new opportunities. This paper provides an overview on mHealth growth and the benefits of its combination with big data analysis for various purposes of health care. We outline our proposed framework for mobile-aided diagnostic systems. We also discuss the opportunities and challenges of mHealth in aiding diagnosis through mobile technologies.
\end{abstract}

Keywords: big data, health care, mHealth, mobile-aided diagnostic systems

Citation: Ben Hassen D. Mobile-aided diagnosis systems are the future of health care. East Mediterr Health J. 2020;26(9):1135-1140 https://doi. org/10.26719/emhj.20.042

Received: 23/02/19; accepted: 23/09/19

Copyright (C) World Health Organization (WHO) 2020. Open Access. Some rights reserved. This work is available under the CC BY-NC-SA 3.0 IGO

license (https://creativecommons.org/licenses/by-nc-sa/3.o/igo)

\section{Introduction}

Several terms such as telemedicine, telehealth, eHealth (electronic health) have been used to refer to the use of information technology to support health service delivery and health systems. Transition of these terms to a new term mHealth (mobile health) has become evident in the literature due to the unprecedented spread of mobile technologies as well as advances in their innovative application. As reported by the World Health Organization, mobile health (mHealth) is a subset of eHealth and is defined as the use of mobile wireless technologies for health. More recently, the term digital health was introduced as a broad umbrella term encompassing eHealth (which includes mHealth), as well as emerging areas, such as the use of advanced computing sciences in big data, genomics and artificial intelligence (1). The greater personal access to smartphones worldwide was the motivation behind the development of the mHealth field. This new field has emerged in recent years and offers the ability of remote individuals to participate in health care, which may not have been possible in the past.

The most common application of mHealth is the use of mobile phones and communication devices to educate consumers about preventive healthcare services. However, mHealth is also used for chronic disease management and to aid diagnosis of complex diseases (2). Hence, mHealth devices generate a large amount of data and in order to obtain the maximum benefit from mHealth data, emerging big data technologies can be used. Analysis of big data in aggregate form at different stages has potential in various purposes.

This paper is organized as follows: after commenting on the benefits of using mHealth in decision-making, we describe the contribution of mobile health and big data in various aspects of healthcare services. We then presents computerized schemes for our proposed system, and finally, we discuss the opportunities and challenges, as well as the directions for future research in this field.

\section{mHealth overview}

From text reminders to virtual clinic visits, the proliferation of mobile health apps has greatly improved patient outcomes as well as the overall quality of healthcare provided (3). Tens of thousands of mobile health apps are now available for downloading from online stores. These apps enable clinicians to save time by allowing them to access patient information more efficiently (4). Besides, they allows patients particularly with chronic diseases to prevent complications and obtain alarms in abnormal situations that can be viewed by doctors in real time (5). A recent report by the Mobile Health Market notes that $80 \%$ of physicians use smartphones and medical apps as healthcare tools and innovative platforms for doctor/patient interaction (6).

Smartphones are the most commonly used mobile devices in our daily life. They are the most prominent platforms for mHealth applications. mHealth apps can perform a variety of functions related to self-monitoring such as weight management, activity levels and smoking cessation by tracking personal data including daily calorie intake, heart rate, glucose level and even brain activity. Thus, healthcare providers can keep patients under continuous observation and detect the symptoms at an early stage to treat them more effectively.

Therefore, many studies have evaluated the effect of mobile health apps on the experience of patients and physicians. mHealth is already being applied and tested in diverse health contexts, such as Parkinson's disease and maternal and child health (7), and diabetes is the most investigated condition $(8,9)$. The popularity of mobile health for management of diabetes is growing. The Community Preventive Services Task Force 
recommends the use of diabetes self-management mobile apps in healthcare systems (10). There is a general overview of various applications of mHealth for diabetes care, for example, to obtain monitoring data and measuring glycaemic management outcomes (5). Most evidence on mHealth for diabetes relies on advanced features of smartphones that can improve diabetes selfmanagement. Another key development of mobile apps is notifying parents of the condition of their children with diabetes as well as child-parent communication.

Mobile health studies are not restricted to those cited above. They are growing exponentially, dealing with many areas and intersecting with others. This exponential growth has greatly affected health care and has outpaced the science (11). Table 1 shows a selection of studies illustrating the potential of applying mHealth.

\section{mHealth and big data technologies}

The health domain generates large amounts of quantitative (e.g., laboratory tests and images) and qualitative (e.g., electronic health records and clinical notes) data that are utilized in diagnosis and treatment. Notably, the field of medical image storage and analysis has grown exponentially, with an increase in data set sizes. Physicians are asked, in their daily work, to examine hundreds of computed tomography (CT), magnetic resonance, positron emission tomography or X-ray images and to diagnose complex diseases. This large volume of data is exploited for decision-making purposes. Indeed, medical images are not simple data, and they are usually overloaded with heterogeneous data from different sources. For these reasons, there are many isolated databases of semistructured and unstructured valuable data in health care.

Mobile technologies enable clinicians to collect all this health data easily, by smart applications, smart devices, and Internet of Things sensors, from a diverse set of sources. The term Internet of Things refers to the connection of physical objects to the Internet (16).
However, it is difficult to process these data using traditional database management tools, especially data that do not have a common structure. With the help of mobile devices that continuously produce large amounts of structured and unstructured data, mHealth data have turned into big data. mHealth has the potential to store and process efficiently big data that are increasing exponentially in quantity over time, from a large number of usually disparate data sources. Currently, big data technologies are increasingly being used to solve the problems of data storage and management for biomedical and healthcare informatics research (17). Hence, with the ability to deal with large volumes, big data hold the promise of storage of medical images and offer the analytical tools to investigate them. There are 5 unique characteristics of big data that distinguish them from ordinary data: volume, velocity, variety, veracity and value (18). Volume refers to the size of data, which is clearly the most important characteristic of the big data. Velocity refers to the speed of the data that need to be processed in real time. Variety refers to the distinct types of data. Veracity is related to the quality of the collected data. Finally, value reflects the benefits of big data analytics. Big data can often produce an extensive amount of health statistics that are discussed in the context of improving medical care and preventing disease (19). Moreover, big data can transform mHealth data into meaningful information and could benefit clinicians and patients through knowledge read on a mobile platform.

So, mHealth integrates mobile computing, medical sensors and portable devices in order to promote the development of emerging systems and applications for health care. To obtain the optimum benefits of mHealth, it needs to work with big data as an integrated tool. The mHealth apps based on big data are a fast-growing field, with many new studies published in recent years, such as the successful application in which the authors have proposed a learning scheme for patients' activity recognition (20). The mutual relation between mHealth and big data makes it easier to study and monitor

\begin{tabular}{|c|c|c|c|c|}
\hline Area & Sample & Methods & Data type & Refs \\
\hline Skin cancer care & $\begin{array}{l}228 \text { participants aged } \\
50-64 \text { years at high risk of } \\
\text { melanoma }\end{array}$ & Mobile dermascopes & $\begin{array}{l}\text { Questionnaire } \\
\text { Preteledermoscopy and } \\
\text { skin self-photographs }\end{array}$ & (12) \\
\hline Tuberculosis diagnostics & $\begin{array}{l}4701 \text { images ( } 4248 \text { with } \\
\text { manifestations) from Peru }\end{array}$ & $\begin{array}{l}\text { Mobile computing and deep } \\
\text { learning }\end{array}$ & $\begin{array}{l}\text { Image capturing and } \\
\text { transmission by mobile } \\
\text { device. } \\
\text { Annotated X-ray. Images and } \\
\text { data analytics }\end{array}$ & (13) \\
\hline Multimedia mHealth application & $\begin{array}{l}\text { Users of hyperbaric oxygen } \\
\text { therapy chamber }\end{array}$ & Virtual reality & $\begin{array}{l}\text { 3D stereoscopic virtual } \\
\text { reality glasses and } \\
\text { immersive perception }\end{array}$ & (14) \\
\hline Internet of Things & 23 patients & $\begin{array}{l}\text { Wearable devices and mobile } \\
\text { apps to monitor oxygen } \\
\text { saturation and heart rate }\end{array}$ & $\begin{array}{l}\text { An alarm was sent to } \\
\text { clinicians in the event of } \\
\text { oxygen saturation below } \\
90 \% \text {, heart rate above } 140 \text { or } \\
\text { below } 60 \text { bpm }\end{array}$ & (15) \\
\hline
\end{tabular}


patients' health status and has the potential to achieve higher quality care at lower costs and with better overall outcomes (21).

\section{New horizons of mobile-aided diagnos- tic systems}

The uncertain nature of the diagnosis of many diseases makes diagnostic decisions difficult. Several emerging technologies are involved in the diagnostic process, such as telemedicine. The use of mHealth in diagnosis is a recent phenomenon. Studies have shown that mHealth can improve decision-making opportunities (22). mHealth plays key roles in various aspects of the diagnostic process. One recent study has proposed that mHealth technology can be integrated into medical decision-making for patients with advanced knee arthritis (23).

Other recent studies have begun talking about mobileaided diagnostic systems such as an android smartphone app (24) that detects the optic nerve head in retinal fundus images in order to identify diabetic retinopathy as well as other abnormalities in eye examinations. Association of a mobile application and a computer-aided diagnostic system has been proposed for diagnosis of skin nodules (25).

Despite the continuous development of mobile platforms in terms of processing power, storage capacity and captured image quality, current mHealth technologies were developed for simple measurements and do not have the capabilities to address the challenges of diagnosis of complex diseases such as breast cancer and cardiovascular disease.

The main objective of our research is to design a secure, simple to use, efficient and intelligent mobileaided diagnostic big data system. As shown in Figure 1,

\section{Figure 1 Graphic presentation of our proposed framework for a mobile-aided diagnostic system}

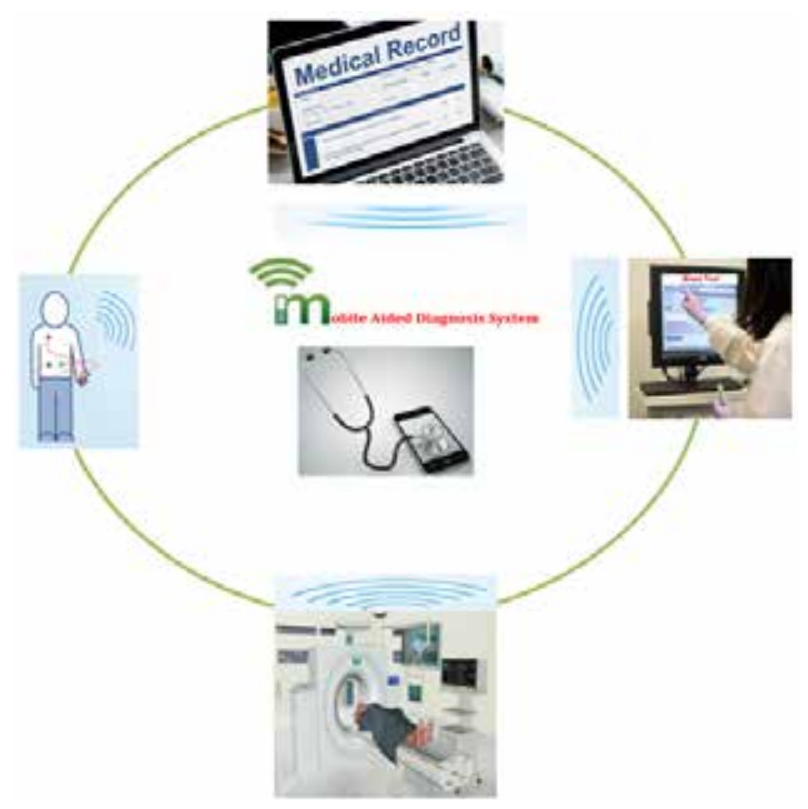

our proposed system utilizes traditional client-server architecture, which includes a client using a smartphone and a server (cloud computing service). The client and server communicate via a cellular network. Wearable and sensor technologies are key to development of our mHealth project. Wearable systems are intended to facilitate data collection, and they offer an additional source of patient data that may improve clinicians' ability to diagnose certain conditions. Additionally, with the rapid development of wireless communication and sensor technologies, mobile phones and tablets have increasingly stronger computing and sensing capacities (26).

Thanks to the use of wearable sensors, it is possible to collect and analyse the data coming from these devices to monitor patients' health status, such as heart rate and blood pressure. Currently, this feature allows acquisition of vital data but it does not process the other medical data to diagnosis serious diseases. We intend to connect with sensors different medical modalities, such as imaging, cell-based assays and even electronic records. This will generate a large amount of significant data. To handle the large volume of data and achieve ease of use, cloud computing technology is the solution. In fact, the development of cloud computing has been of paramount importance to big data and will play a major role in our proposed infrastructure that can be used for various purposes like construction of an electronic archive.

Additionally, the use of this system can influence positively communication and relationships between patients and providers, facilitating relationship-centred health care (27). The clinician-patient relationship is an important determinant of quality health care (28). The mHealth revolution has a positive impact on how doctors/nurses interact with patients. In the future, faceto-face healthcare provider/patient contacts will become less common and exchanges between consumers and providers will increasingly be mediated by smartphones.

Our proposed infrastructure will forever change the way providers and consumers interact. It will mediate almost all information and will be the source of almost everything that doctors and other clinicians will learn about their patients. Patient information will be accessible to all providers anywhere and anytime and this access of course will be limited to only those clinicians to whom the patient grants access. Patients will have electronic access to almost as much information about their condition and the medical evidence base as their healthcare providers have. Finally, it is essential that clinicians and researchers understand how to adopt and adapt this transformation of the healthcare systems of the future.

\section{Ethical and interoperability issues}

Information about individuals can be collected without the people even noticing. Health data are sensitive, and their granularity presents significant challenges to anonymizing personal information, and this exposes consumers to privacy and data security risks (29). The 
ethical requirement is to keep sensitive and identifiable information confidential. With the growth mHealth technologies, healthcare professionals have encountered an emerging new set of ethical issues relating to privacy (30). The classical medical ethics principles of autonomy, beneficence, nonmaleficence and justice can be used to address ethical dimensions of mHealth application design. User autonomy is the issue of trust to the service that is offered and its provider. Beneficence obligates the healthcare professional to promote good and provide assistance to others. Nonmaleficence is the principle that one should do no harm. Justice requires that all people be treated fairly and equally (30). Health technology should be safe and secure and its applications should not violate privacy and trust. Therefore, protection of patient data has always been a principal concern within the eHealth field. The evolution of technology to mobile health platforms has made the issue more complex. Certainly the use of mobile devices has raised new concerns for data privacy and security. With many things being connected, new security and privacy problems arise, for example, confidentiality, authenticity and integrity of data sensed and exchanged.

Problems of data security in mHealth have been tackled by numerous researchers. Many studies have used standards to ensure the security and privacy of their mobile apps, such as an app that utilizes data encrypted using Secure Shell (31). However, the lack of specific strategies and mechanisms to ensure adequate security and privacy to maximize the full capabilities of mobile devices presents a significant barrier to care. The interoperability problem, in a Wi-Fi-based environment, could be solved through many traditional methods such as a Wi-Fi/Bluetooth gateway or by using Web services. The health data are transmitted in plain text using the JSON format, which represents a security weakness because it allows eavesdropping during the connection.

\section{Discussion and conclusion}

mHealth combined with big data is fast becoming a new prospect in the world of health and has potential benefits.
This new field refers to electronic health data so large and complex that they are difficult to manage with traditional software and computing algorithms. With more computing power and high-quality imaging, it will be beneficial if doctors receive on their smartphones patient files, CT scans and blood test results. Furthermore, intelligent mobile apps can help with diagnosis. This revolution in mobile-aided diagnostic systems will offer opportunities to manage complex diseases and save time and money. Mobile-aided diagnostic systems are predicted to influence profoundly the future of health care. Although these systems are opening a new generation of innovation applications, several challenges exist.

We think that the main challenge in developing mHealth technologies for complex diseases is the medical infrastructure, especially in low-resource countries. Another challenge is to bring this innovation to clinics and introduce the new equipment to medical staff.

Furthermore, there is a need to improve its usability and security. The impact of mHealth on the work of nurses and physicians must be also analysed. By giving doctors real-time statistics, mobile-aided diagnostic systems could improve population health and reduce healthcare costs. Mobile-aided diagnostic systems have a potentially role to play in preventing disease. They can allow the discovery of relationships between disease and lifestyle or the environment. This helps people to successfully modify their risk behaviours.

Finally, creative use of mHealth, such as mobile-aided diagnostic systems, has the potential to reduce the cost of health care and improve well-being in numerous ways. These applications are making health services more efficient and sustainable, but rigorous research is needed to examine the potential, as well as the challenges, of utilizing mobile technologies to improve health outcomes.

Funding: None.

Competing interests: None declared. 


\section{Les systèmes de diagnostic assistés par téléphone portable : l'avenir des soins de santé Résumé}

La technologie est génératrice de changements dans les tâches courantes des médecins. Les progrès en matière de technologies mobiles ont donné naissance à un nouveau terme : la santé mobile. Les dispositifs de santé mobile génèrent des mégadonnées («big data »); l'intégration de la santé mobile et des mégadonnées dans les services déjà existants de cybersanté, ainsi que le développement constant de la couverture par les réseaux de téléphonie mobile, ouvrent de nouvelles perspectives. Le présent article fournit une vue d'ensemble du développement de la santé mobile et des avantages de son association avec l'analyse des mégadonnées pour de nombreuses applications des soins de santé. Nous présentons une proposition de cadre pour les systèmes de diagnostic assistés par téléphone portable. Nous examinons également les perspectives et les enjeux de la santé mobile en matière d'aide au diagnostic par les technologies mobiles.

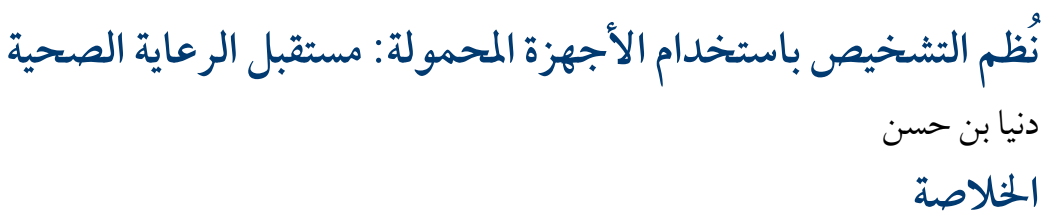

\section{References}

1 WHO guideline: recommendations on digital interventions for health system strengthening. Geneva: World Health Organization; 2019 (https://www.who.int/reproductivehealth/publications/digital-interventions-health-system-strengthening/en/, accessed 1 April 2020).

2 Miller AS, Cafazzo JA, Seto E. A game plan: gamification design principles in mHealth applications for chronic disease management. Health Informatics J. 2016 Jun;22(2):184-93. http://dx.doi.org/10.1177/1460458214537511 PMID:24986104

3 Slovensky DJ, Malvey DM, Neigel AR. A model for mHealth skills training for clinicians: meeting the future now. Mhealth. 2017 Jun 15;3:24. http://dx.doi.org/10.21037/mhealth.2017.05.03 PMID:28736733

4 Marent B, Henwood F, Darking M, EmERGE Consortium. Development of an mHealth platform for HIV care: gathering user perspectives through co-design workshops and interviews. JMIR Mhealth Uhealth. 2018 Oct 19;6(10):e184. http://dx.doi. org/10.2196/mhealth.9856 PMID:30339132

5 Fatehi F, Menon A, Bird D. Diabetes care in the digital era: a synoptic overview. Curr Diab Rep. 2018 May 10;18(7):38. http://dx.doi. org/10.1007/s11892-018-1013-5 PMID:29748905

6 Mobile health trends and figures 2013-2017 [website]. Research and Markets (https://www.researchandmarkets.com/research/ nhc8j7/mobile_health, accessed 1 April 2020).

7 Chen H, Chai Y, Dong L, Niu W, Zhang P. Effectiveness and appropriateness of mHealth interventions for maternal and child health: systematic review. JMIR Mhealth Uhealth. 2018 Jan 9;6(1):e7. http://dx.doi.org/10.2196/mhealth.8998 PMID:29317380

8. Al-Taee MA, Al-Nuaimy W, Al-Ataby A, Muhsin ZJ, Abood SN. Mobile health platform for diabetes management based on the Internet-of-Things. 2015 IEEE Jordan Conference on Applied Electrical Engineering and Computing Technologies (AEECT). Amman; 2015;1-5. https://ieeexplore.ieee.org/document/7360551

9. Wu Y, Yao X, Vespasiani G, Nicolucci A, Dong Y, Kwong J, et al. Correction: Mobile app-based interventions to support diabetes self-management: a systematic review of randomized controlled trials to identify functions associated with glycemic efficacy. JMIR Mhealth Uhealth. 2018 Jan 15;6(1):e20. http://dx.doi.org/10.2196/mhealth.8789 PMID:29334479

10. Diabetes management: mobile phone applications used within healthcare systems for type 2 [website]. The Community guide; 2017 (https://www.thecommunityguide.org/findings/diabetes-management-mobile-phone-applications-used-within-healthcare-systems-type-2, accessed 1 April 2020).

11. Kumar S, Nilsen WJ, Abernethy A, Atienza A, Patrick K, Pavel M, et al. Mobile health technology evaluation: the mHealth evidence workshop. Am J Prev Med. 2013 Aug;45(2):228-36. http://dx.doi.org/10.1016/j.amepre.2013.03.017 PMID:23867031

12. Horsham C, Loescher LJ, Whiteman DC, Soyer HP, Janda M. Consumer acceptance of patientDperformed mobile teledermoscopy for the early detection of melanoma. Br J Dermatol. 2016 Dec;175(6):1301-10. http://dx.doi.org/10.1111/bjd.14630 PMID:27037999 
13. Alcantara MF, Cao Y, Liu C, Liu B, Brunette M, Zhang N, Albarracin CM et al. Improving tuberculosis diagnostics using deep learning and mobile health technologies among resource-poor communities in Peru. Smart Health. 2017 Jun;1-2:66-76. https:// doi.org/10.1016/j.smhl.2017.04.003

14. Lv Z, Chirivella J, Gagliardo P. Bigdata oriented multimedia mobile health applications. J Med Syst. 2016 May;40(5):120. http:// dx.doi.org/10.1007/s10916-016-0475-8 PMID:27020918

15. Lee JH, Park YR, Kweon S, Kim S, Ji W, Choi CM. A cardiopulmonary monitoring system for patient transport within hospitals using mobile internet of things technology: observational validation study. JMIR Mhealth Uhealth. 2018 Nov 14;6(11):e12048. http://dx.doi.org/10.2196/12048 PMID:30429115

16. Karkouch A, Mousannif $\mathrm{H}, \mathrm{Al}$ Moatassime H, Noel T. A model-driven framework for data quality management in the Internet of Things. J Ambient Intell Humanized Comput. 2018;9(4),977-98. https://doi.org/10.1007/s12652-017-0498-0

17. Omboni S, Caserini M, Coronetti C. Telemedicine and $\mathrm{m}$-health in hypertension management: technologies, applications and clinical evidence. High Blood Press Cardiovasc Prev. 2016 Sep;23(3):187-96. http://dx.doi.org/10.1007/s40292-016-0143-6 PMID:27072129

18. Andreu-Perez J, Poon CC, Merrifield RD, Wong ST, Yang GZ. Big data for health. IEEE J Biomed Health Informatics. 2015;19(4):1193-208. https://ieeexplore.ieee.org/stamp/stamp.jsp?arnumber=7154395

19. Luo J, Wu M, Gopukumar D, Zhao Y. Big data application in biomedical research and health care: a literature review. Biomed Inform Insights. 2016 Jan 19;8:1-10. http://dx.doi.org/10.4137/BII.S31559 PMID:26843812

20. Guo J, Zhou X, Sun Y, Ping G, Zhao G, Li Z. Smartphone-based patients' activity recognition by using a self-learning scheme for medical monitoring. J Med Syst. 2016 Jun;40(6):140. http://dx.doi.org/10.1007/s10916-016-0497-2 PMID:27106584

21. Gökalp MO, Kayabay K, Akyol MA, Koçyiğit A, Eren PE. Big data in mHealth. In: Sezgin E, Yildirim S, Özkan-Yildirim S, Sumuer E, editors. Current and emerging mHealth technologies. Springer; 2018:241-56. https://doi.org/10.1007/978-3-319-73135-3_15

22. Abbasgholizadeh Rahimi S, Menear M, Robitaille H, Légaré F. Are mobile health applications useful for supporting shared decision making in diagnostic and treatment decisions? Glob Health Action. 2017 Jun;10(Suppl 3):1332259. http://dx.doi.org/10.1080/16 549716.2017.1332259 PMID:28838306

23. Zheng H, Tulu B, Choi W, Franklin P. Using mHealth app to support treatment decision-making for knee arthritis: patient perspective. EGEMS. 2017 Apr 20;5(2):7. http://dx.doi.org/10.13063/2327-9214.1284 PMID:29930969

24. Elloumi Y, Akil M, Kehtarnavaz N. A mobile computer aided system for optic nerve head detection. Comput Methods Programs Biomed. 2018 Aug;162:139-48. https://doi.org/10.1016/j.cmpb.2018.05.004

25. Thamizhvani TR, Lakshmanan S, Sivaramakrishnan R. Mobile application-based computer-aided diagnosis of skin tumours from dermal images. Imaging Sci J. 2018;66(6):382-91. http://dx.doi.org/10.1080/13682199.2018.1492682

26. Chen M, Mao S, Liu Y. Big data: a survey. Mobile Netw Appl. 2014;19:171-209. https://doi.org/10.1007/s11036-013-0489-0

27. Qudah, B., \& Luetsch, K. (2019). The influence of mobile health applications on patient-healthcare provider relationships: a systematic, narrative review. Patient Educ Counsel. 2019 Jun;102(6):1080-9. https://doi.org/10.1016/j.pec.2019.01.021

28. Strengthening the doctor-patient relationship. New Delhi: World Health Organization Regional Office for South-East Asia; 2013 (https://apps.who.int/iris/handle/10665/205942, accessed 1 April 2020).

29. Tarouco LMR, Bertholdo LM, Granville LZ, Arbiza LMR, Carbone F, Marotta M. et al. Internet of Things in healthcare: interoperatibility and security issues. 2012 IEEE International Conference on Communications (ICC), Ottawa; 2012:6121-5. https://ieeexplore.iee.org/document/6364830

30. Francis I. Using classical ethical principles to guide mHealth design. Online J Nurs Informatics. 2017 Fall;21(3). (https://www. researchgate.net/publication/339004012_Using_Classical_Ethical_Priniples_to_Guide_mHealth_Design.

31. Cao Y, Liu C, Liu B, Brunett MJ, Zhang N, Sun T, et al. Improving tuberculosis diagnostics using deep learning and mobile health technologies among resource-poor and marginalized communities. 2016 IEEE First International Conference on Connected Health: Applications, Systems and Engineering Technologies (CHASE), Washington, DC;2016:274-81. https://ieeexplore.ieee.org/ document/7545842 